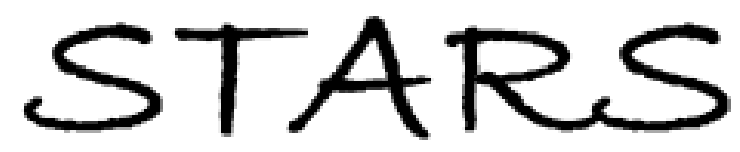

University of Central Florida

STARS

$1-1-2000$

\title{
Feasibility tests of transmission x-ray photoelectron emission microscopy of wet samples
}

\author{
Gelsomina De Stasio \\ B. Gilbert \\ T. Nelson \\ R. Hansen \\ J. Wallace
}

See next page for additional authors

Find similar works at: https://stars.library.ucf.edu/facultybib2000

University of Central Florida Libraries http://library.ucf.edu

This Article is brought to you for free and open access by the Faculty Bibliography at STARS. It has been accepted for inclusion in Faculty Bibliography 2000s by an authorized administrator of STARS. For more information, please contactSTARS@ucf.edu.

\section{Recommended Citation}

Stasio, Gelsomina De; Gilbert, B.; Nelson, T.; Hansen, R.; Wallace, J.; Mercanti, D.; Capozi, M.; Baudat, P. A.; Perfetti, P.; Margaritondo, G.; and Tonner, B. P., "Feasibility tests of transmission x-ray photoelectron emission microscopy of wet samples" (2000). Faculty Bibliography 2000s. 2490.

https://stars.library.ucf.edu/facultybib2000/2490

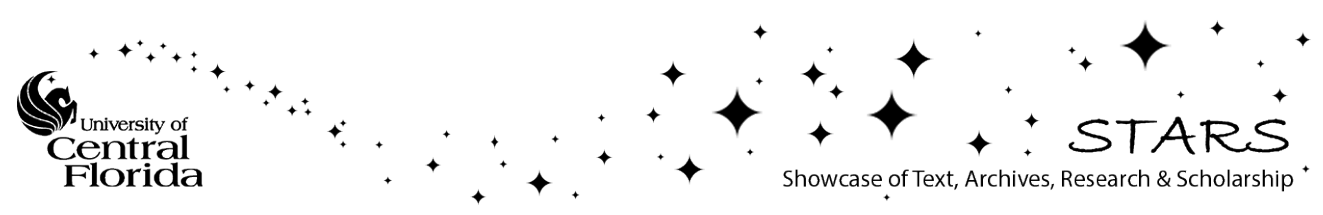




\section{Authors}

Gelsomina De Stasio, B. Gilbert, T. Nelson, R. Hansen, J. Wallace, D. Mercanti, M. Capozi, P. A. Baudat, P. Perfetti, G. Margaritondo, and B. P. Tonner 


\section{Feasibility tests of transmission x-ray photoelectron emission microscopy of wet samples}

Cite as: Review of Scientific Instruments 71, 11 (2000); https://doi.org/10.1063/1.1150151

Submitted: 01 August 1999 . Accepted: 07 October 1999. Published Online: 28 December 1999

Gelsomina De Stasio, B. Gilbert, T. Nelson, R. Hansen, J. Wallace, D. Mercanti, M. Capozi, P. A. Baudat, P. Perfetti, G. Margaritondo, and B. P. Tonner

\section{ARTICLES YOU MAY BE INTERESTED IN}

Table-top water window transmission x-ray microscopy: Review of the key issues, and conceptual design of an instrument for biology

Review of Scientific Instruments 76, 091301 (2005); https://doi.org/10.1063/1.2018633

X-ray absorption microscopy of aqueous samples

Review of Scientific Instruments 73, 1373 (2002); https://doi.org/10.1063/1.1423623

Angle-resolved photoemission spectroscopy with a femtosecond high harmonic light source using a two-dimensional imaging electron analyzer

Review of Scientific Instruments 78, 083105 (2007); https://doi.org/10.1063/1.2773783

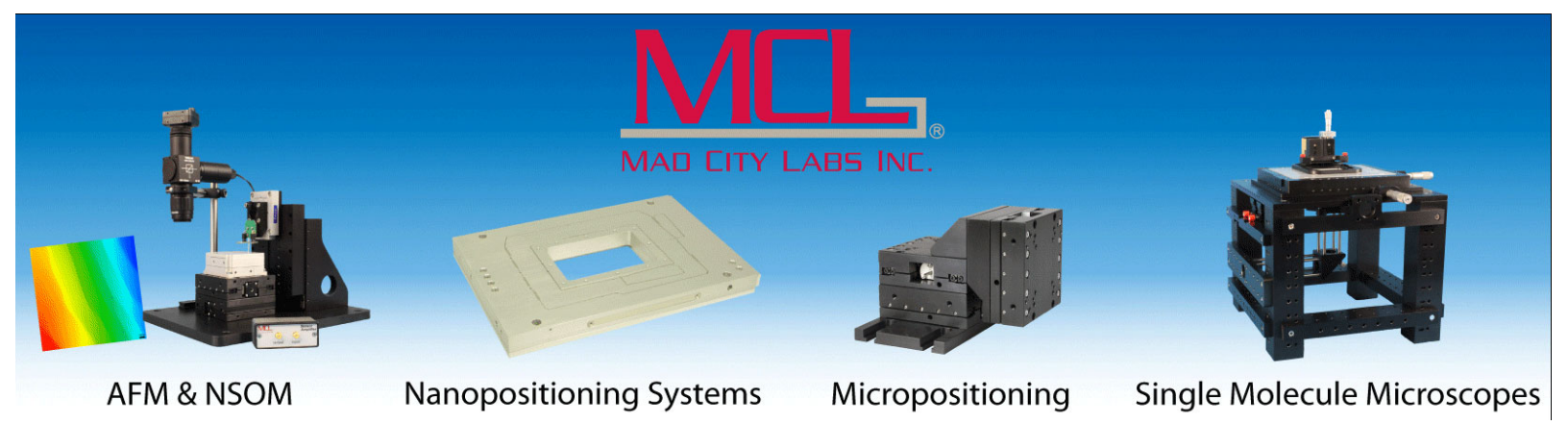




\title{
Feasibility tests of transmission x-ray photoelectron emission microscopy of wet samples
}

\author{
Gelsomina De Stasio \\ Istituto di Struttura della Materia del CNR, Via Fosso del Cavaliere, I-00133 Roma, Italy and University \\ of Wisconsin at Madison, Physics Department, 1150 University Avenue, Madison, Wisconsin 53706 \\ B. Gilbert \\ Institut de Physique Appliquée, Ecole Polytechnique Fédérale, CH-1015, Lausanne, Switzerland \\ T. Nelson, R. Hansen, and J. Wallace \\ Synchrotron Radiation Center, University of Wisconsin-Madison, 3731 Schneider Drive, Stoughton, \\ Wisconsin 53589 \\ D. Mercanti \\ Istituto di Neurobiologia del CNR, Viale Marx 15, I-00137 Roma, Italy \\ M. Capozi \\ Istituto di Struttura della Materia del CNR, Via Fosso del Cavaliere, I-00133 Roma, Italy \\ P. A. Baudat \\ Institut de Physique Appliquée, Ecole Polytechnique Fédérale, CH-1015, Lausanne, Switzerland \\ P. Perfetti \\ Istituto di Struttura della Materia del CNR, Via Fosso del Cavaliere, I-00133 Roma, Italy \\ G. Margaritondo \\ Institut de Physique Appliquée, Ecole Polytechnique Fédérale, CH-1015, Lausanne, Switzerland \\ B. P. Tonner \\ Department of Physics, University of Central Florida, Orlando, Florida 32718
}

(Received 1 August 1999; accepted for publication 7 October 1999)

\begin{abstract}
We performed feasibility tests of photoelectron emission spectromicroscopy of wet samples in the water window $(285-532 \mathrm{eV})$ soft $\mathrm{x}$-ray spectral region. Water was successfully confined in an ultrahigh vacuum compatible compartment with $\mathrm{x}$-ray transparent sides. This water cell was placed in the MEPHISTO spectromicroscope in a transmission geometry, and complete $\mathrm{x}$-ray absorption spectra of the water window region were acquired. We also show micrographs of test samples, mounted outside of the compartment, and imaged through the water. This technique can be used to study liquid chemistry and, at least to the micron level, the microstructure of wet samples. Possibilities include cells in water or buffer, proteins in solution, oils of tribological interest, liquid crystals, and other samples not presently accessible to the powerful x-ray photoelectron emission spectromicroscopy technique. () 2000 American Institute of Physics. [S0034-6748(00)04501-9]
\end{abstract}

\section{INTRODUCTION}

We recently ${ }^{1,2}$ reported the commissioning of the $\mathrm{x}$-ray photoelectron emission microscopy (X-PEEM) named MEPHISTO from the French acronym "Microscope à Emission de PHotoélectrons par Illumination Synchrotronique de type Onduleur." The same instrument can also operate in the transmission mode, ${ }^{3,4}$ with synchrotron $\mathrm{x}$ rays transmitted through the specimen, and converted into photoelectrons by a photocathode. We now extended the possible applications of transmission spectromicroscopy with MEPHISTO to liquid samples. This allows the possibility of biological and microchemical studies of elements and macromolecules in solution, particles in suspension, oils, and other samples that are not ultrahigh vacuum (UHV) compatible, and until now impossible to analyze with PEEM techniques.

An application of particular interest is the study of biological materials in their natural hydrated state. The wet compartment for spectromicroscopy described here does not allow the imaging of living cells because the radiation dose delivered is presently too high for real data acquisition, as discussed below. However, fixed cells, wet proteins, or other chemical solutions may be studied within the $\mathrm{x}$-ray energy range termed the water window. The water window is the soft x-ray energy range between the carbon and the oxygen absorption $K$ edges, in which water has a much lower x-ray attenuation coefficient than carbon-containing cells. All $\mathrm{x}$-ray analysis of biological samples causes damage, mostly through the formation of $\mathrm{O}$ and $\mathrm{OH}^{-}$free radicals, which at high radiation doses will kill cells, but lower doses may also provoke nonfatal DNA damage. ${ }^{5,6}$

During the present tests the MEPHISTO system was installed on the Aladdin storage ring of the University of Wisconsin Synchrotron Radiation Center, on the $10 \mathrm{~m}$ toroidal grating monochromator (TGM) beamline, where for a beam current of $200 \mathrm{~mA}$ and slits at $400 \mu \mathrm{m}$, the photon flux 
available on the sample is on the order of $10^{11}$ photons/s in the water window region. The spot size on the sample is approximately $300 \times 700 \mu \mathrm{m}^{2}$ and the thicknesses of the $\mathrm{Si}_{3} \mathrm{~N}_{4}$ membrane and water compartment are 0.2 and $3 \mu \mathrm{m}$, respectively. The rate of energy absorption by the irradiated water area is given by

$$
\frac{d E_{\mathrm{abs}}}{d t}=\Phi E\left(1-e^{-\mu \rho \Delta}\right) e^{-\mu_{w} \rho_{w} \delta},
$$

where the units of absorbed energy $E_{\text {abs }}$ are $\mathrm{J} \mathrm{cm}^{2} \mathrm{~s}^{-1}, \Phi$ is the photon flux per unit area, $E=h \nu$ is the photon energy in Joules $\left(1 \mathrm{eV}=1.6 \times 10^{-19} \mathrm{~J}\right), \mu$ is the mass attenuation coefficient, $\rho$ and $\Delta$ are the density and thickness of the absorbing material. The factor $\exp \left(-\mu_{w} \rho_{w} \delta\right)$ considers the absorption of the silicon nitride membrane. Taking the values for pure $\mathrm{Si}$ and $300 \mathrm{eV}$ photons $\left(\mu_{w}=2.7 \times 10 \mathrm{~cm}^{2} \mathrm{~g}^{-1}, \rho_{w}\right.$ $=2.32 \mathrm{~g} \mathrm{~cm}^{-1}$ ) we estimate this factor to be on the order of $1 / 3$. For water, $\mu(300 \mathrm{eV})=4.49 \times 10^{3} \mathrm{~cm}^{2} \mathrm{~g}^{-1}$, and $\mu(500 \mathrm{eV})=1.28 \times 10^{3} \mathrm{~cm}^{2} \mathrm{~g}^{-1}$. ${ }^{7}$ To convert to units of radiation dose (energy absorbed per $\mathrm{kg}$ ), a water film of thickness $3 \mu \mathrm{m}$ has a mass of $3 \times 10^{-7} \mathrm{~kg} \mathrm{per \textrm {cm } ^ { 2 }}$. The $e^{-1}$ attenuation depth in water of $300 \mathrm{eV} x$ rays is on the order of $2 \mu \mathrm{m}$, so we assume the energy to be absorbed homogeneously within the water compartment.

Therefore, the radiation dose at $300 \mathrm{eV}$ is $12 \mathrm{~Gy} \mathrm{~s}^{-1}$ and at $500 \mathrm{eV}$ is $6 \mathrm{~Gy} \mathrm{~s}^{-1}$, where $1 \mathrm{~Gy}=1 \mathrm{~J} \mathrm{~kg}^{-1}$.

The minimum time necessary to focus on a sample and acquire an image is one minute, and the corresponding minimum dose at $300 \mathrm{eV}$ is $7.1 \times 10^{3} \mathrm{~Gy}$ and at $500 \mathrm{eV}$ is 3.3 $\times 10^{3} \mathrm{~Gy}$. Such doses are at present too high to allow the study of living cells, since already at 10 Gy there is $99 \%$ cell mortality. ${ }^{5}$ Future developments to increase the transmission of the electrostatic optics may allow spectromicroscopy with a lower photon flux and consequently a lower radiation dose. Freezing the sample and keeping it frozen during the PEEM experiment can limit radiation damage during the exposure to $\mathrm{x}$-ray photons, as reactive free radicals are trapped in the ice. This approach, however, is not viable for observing dynamic processes in living cells, such as transport or signaling.

Other non-UHV spectromicroscopy techniques, including the full-field and scanning approaches, have already demonstrated their performances on wet samples. ${ }^{8-10}$ To our knowledge, the present data represent the first evidence of the feasibility of wet sample X-PEEM in UHV.

\section{MATERIALS AND METHODS}

We designed and built a sample holder that can be transferred into UHV within $30 \mathrm{~min}$, and that allows the confinement of water between two silicon nitride $\left(\mathrm{Si}_{3} \mathrm{~N}_{4}\right)$ windows (from FaSTec Ltd, UK), as shown in the schematic of Fig. 1 (not to scale). The 200-nm-thick, $1 \times 1 \mathrm{~mm}^{2} \mathrm{Si}_{3} \mathrm{~N}_{4}$ windows are held by two $10 \times 10 \mathrm{~mm}^{2}$ silicon wafers. One of them is lithographically patterned with a 3 - $\mu$ m-thick photoresist spacer, which ensures that the water layer between the two windows is $3 \mu \mathrm{m}$ thick. A thicker layer, in fact would not be $\mathrm{x}$-ray transparent. The two silicon wafers are sealed at their edges to prevent evaporation of water with Torr Seal ${ }^{\circledR}$ (from

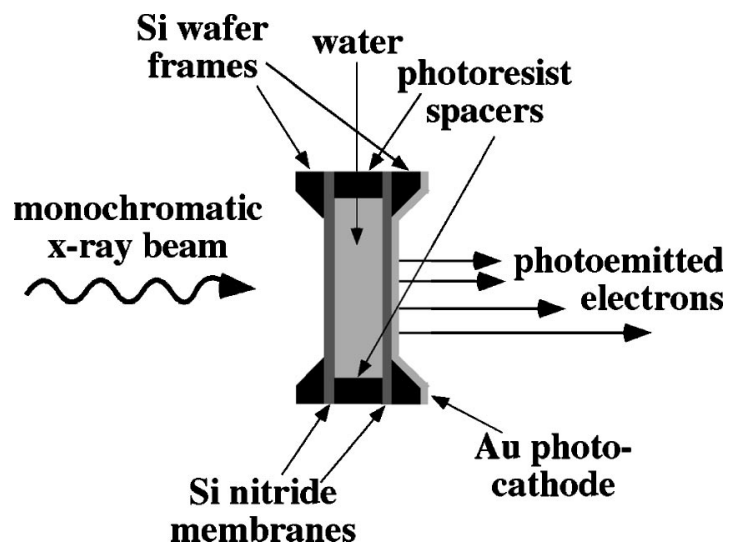

FIG. 1. Schematic diagram of water cell. The photoresist spacers that define the water volume are 3 - $\mu$ m-thick, the $1 \times 1 \mathrm{~mm}^{2} \mathrm{Si}_{3} \mathrm{~N}_{4}$ membranes are 200 $\mathrm{nm}$ thick, the photocathode is a 285 - $\AA$-thick evaporated gold layer. The photocathode was evaporated onto one side of the water cell at several incidence angles to ensure a continuous electrical contact between the window region of the photocathode and the outer edges which were held at high voltage for photoelectron imaging.

Varian, USA), an UHV-compatible double component epoxy. The novelty of this sealing method is that the Torr Seal ${ }^{\circledR}$ was cured with ultraviolet light from a low pressure mercury lamp, for 30-90 min. This method is an alternative to conventionally curing Torr Seal at high temperature, and was developed because most organic materials would be altered by heat treatment. Although UV light can induce chemical damage, the $\mathrm{Si}_{3} \mathrm{~N}_{4}$ membrane, and hence the contents of the compartment can be simply screened during exposure.

\section{RESULTS AND DISCUSSION}

The unit proved to be vacuum compatible and durable. We acquired the spectra of Fig. 2 across the water window $(250-600 \mathrm{eV})$ as soon as the sample was prepared and again from the very same sample after 3.5 days at the UHV pressure of $2 \times 10^{-9}$ Torr. In Fig. 2 the oxygen $K$ edge at $532 \mathrm{eV}$ is predominant. Above this energy very little signal is transmitted because oxygen (from water) absorbs x-ray photons. Below the edge $(480-530 \mathrm{eV})$ the transmission reaches a maximum. At $400 \mathrm{eV}$ we see the nitrogen $K$ edge, due to the $\mathrm{Si}_{3} \mathrm{~N}_{4}$ windows, at $288 \mathrm{eV} \mathrm{C} 1 s$ due to carbon contamination on the upstream (incident beam) side of the $\mathrm{Si}_{3} \mathrm{~N}_{4}$ membrane. A sparse distribution of plastic spheres had been deposited on this membrane from a water suspension, which left additional carbon-containing fine debris after drying. The edge at $266 \mathrm{eV}$ is $\mathrm{O} 1 s$ repeated due to second order radiation from the TGM. Note that after 3.5 days in UHV, the intensity of the $\mathrm{O} 1 \mathrm{~s}$ edge jump is decreased, due to slight water loss, either by leakage in UHV or water absorption by the TorrSeal $^{\circledR}$. The nitrogen edge is unaltered as expected.

We demonstrate that, despite the very limited flux available, it was possible to obtain attenuation contrast in images. Figure 3 shows a MEPHISTO transmission micrograph of 20$\mu \mathrm{m}$-diam polymer spheres (Fractogel, Merk, Germany) that had been deposited on the upstream side of the $\mathrm{Si}_{3} \mathrm{~N}_{4}$ membrane, the spheres were therefore outside the water compartment. The polymer spheres appear dark (strongly absorbing) 
Water Window Transmission Spectra

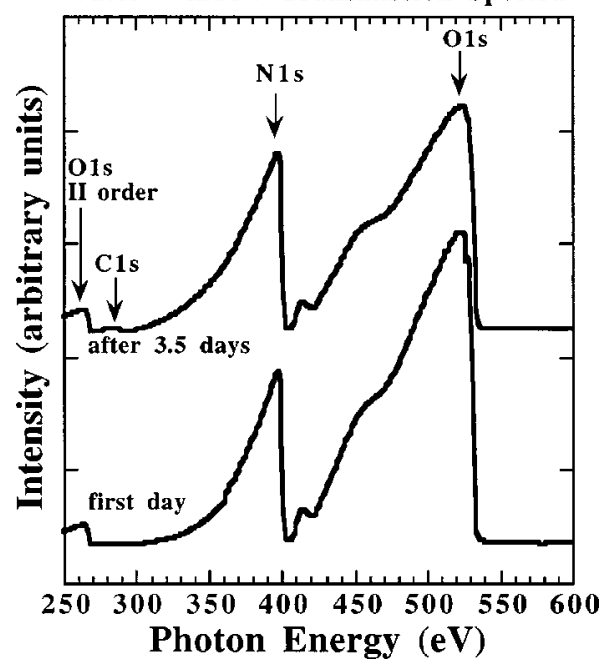

FIG. 2. MEPHISTO x-ray transmission spectrum between 250 and $600 \mathrm{eV}$, including the whole water window region, acquired on a sample mounted as shown in Fig. 1, containing degassed (for $90 \mathrm{~min}$ ) distilled water and sealed with Torr Seal ${ }^{\circledR}$ cured under UV light for $80 \mathrm{~min}$. The monochromator entrance and exit slits were 100 and $250 \mu \mathrm{m}$, the microscopic aperture in the electron optics was selected to be $150 \mu \mathrm{m}$ to increase the signal level. The $\mathrm{O} 1 s$ (from $\mathrm{H}_{2} \mathrm{O}$ ), $\mathrm{N} 1 s$ (from $\mathrm{Si}_{3} \mathrm{~N}_{4}$ ), $\mathrm{O} 1 s$ second order, and $\mathrm{C} 1 s$ (from contaminants) are visible.

in a white (transmitting) background at $525 \mathrm{eV}$ photon energy, just below the oxygen absorption edge. Some contaminant particles are also visible. The micrograph of Fig. 3 captures the shadow of the spheres projected onto the photocathode through the $3 \mu \mathrm{m}$ water gap and $400 \mathrm{~nm}$ of $\mathrm{Si}_{3} \mathrm{~N}_{4}$. X-ray photons that traverse the membranes and the water thickness will in principle be scattered and cause blurring in the shadow image at the photocathode. However, the incoherent scattering cross sections for all elements are very small in the soft $\mathrm{x}$-ray range, so scattering is not expected to account for the poor image quality.

An additional effect was observed which could account for the poor image quality: distortion of the electric field between the photocathode and the first lens component due to the sample geometry. The high $(500 \mu \mathrm{m})$ sharp edges of the silicon wafer around the $1 \times 1 \mathrm{~mm}^{2} \mathrm{Si}_{3} \mathrm{~N}_{4}$ membrane mean that the photocathode is far from being ideally flat. When the sample was set at high voltage $(\sim 15 \mathrm{kV})$ for im-

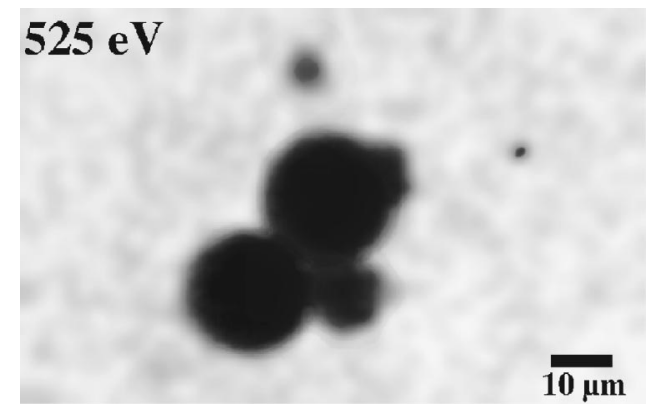

FIG. 3. MEPHISTO x-ray transmission micrograph taken at a photon energy of $525 \mathrm{eV}$, showing $20-\mu \mathrm{m}$-diam plastic microspheres, as well as some other smaller contaminant particles. The spheres were mounted outside the water compartment, on the upstream side of the $\mathrm{Si}_{3} \mathrm{~N}_{4}$ membrane. The monochromator slits were 100 and $500 \mu \mathrm{m}$, and a $50 \mu \mathrm{m}$ microaperture was chosen in the optics to obtain better lateral resolution although trading signal. age and spectra acquisition, the electric field which accelerates the photoelectrons was strongly inhomogeneous, producing a wide angular spread of trajectories. The symptoms of this behavior were that it was not possible to obtain an evenly bright image of a large photocathode area, and that lateral motion of the sample required compensation in the sample angular position to maintain image intensity. This lensing effect reduces the image intensity and creates additional aberrations, especially distortion, in the final image.

The use of larger $\mathrm{Si}_{3} \mathrm{~N}_{4}$ transparent windows would reduce sample geometry distortion effects when imaging at their center. As the mechanical strength of the membranes depends on their area and thickness, larger membranes would certainly be more fragile. Our trials indicate, however, that the stress on the membranes is small at low pressure as long as no pockets of gas were trapped when the compartment was sealed, or appear in the compartment subsequently.

The possibility of bubble formation in the water caused concern for the integrity of the water compartment if dissolved gases were to come out of solution at low pressures. In the first tests we observed in real time the formation of transparent bubbles under x-ray illumination. Repeated tests showed that the appearance of bubbles was not from dissolved gases, and not from radiation induced vaporization of water. In fact bubble appearance was always correlated with pressure fluctuations in the vacuum chamber which signaled a leak in the compartment seal. Once the sealing method with UV curing was optimized this effect was not reproduced, and the water cell was stable even under increased photon flux.

The initial tests used distilled water that had first been degassed by sonication. In later tests, compartments containing nondegassed distilled water, and also nondegassed water from Lake Kegonsa (WI) were stable under vacuum. This demonstrates that the only real concern in this sample mounting is to obtain a watertight seal.

In conclusion, the data show that $\mathrm{x}$-ray absorption spectroscopy of liquid samples is possible with X-PEEM. Biopolymers such as proteins and nucleic acids in solution, oils, and liquid crystals are examples of possible samples now that the carbon $K$ edge can be studied in liquid samples.

We also show that there is sufficient transmitted flux to allow imaging of test objects shadowed onto the photocathode through $3 \mu \mathrm{m}$ water. The next goal is to image carboncontaining fixed cells in the water compartment to reveal the extent of contrast between water and carbon in the water window, and to discover if the transmitted flux will be enough to allow spectromicroscopy in this energy region. It is not possible at present to acquire data from living cells in the water compartment without exceeding the lethal radiation dose. It is conceivable, although technically challenging to develop an X-PEEM that would enable living cell observation. The incident photon flux necessary for imaging could be reduced following two approaches, increasing the transmission of photoelectron through the optics with aberration correction, and improving the detector efficiency. Thinner water compartments ( 1 or $2 \mu \mathrm{m})$ would still accommodate most kinds of cells, and would have the advantage of absorbing a considerably smaller fraction of the photon flux. 
X-PEEM spectromicroscopy of living systems will be performed only in an instrument optimized for low photon flux measurements as indicated.

\section{ACKNOWLEDGMENTS}

Work supported by the Swiss FNSRS, the Italian ISMCNR, and by EPF-Lausanne. The experimental work was performed at the Wisconsin Synchrotron Radiation Center, a national facility supported by the NSF.

${ }^{1}$ G. De Stasio, M. Capozi, G. F. Lorusso, P. A. Baudat, T. C. Droubay, P. Perfetti, G. Margaritondo, and B. P. Tonner, Rev. Sci. Instrum. 69, 2062 (1998).

${ }^{2}$ G. De Stasio, L. Perfetti, B. Gilbert, O. Fauchoux, M. Capozi, P. Perfetti, G. Margaritondo, and B. P. Tonner, Rev. Sci. Instrum. 70, 1740 (1999).

${ }^{3}$ G. De Stasio, G. F. Lorusso, T. Droubay, M. Kohli, P. Muralt, P. Perfetti,
G. Margaritondo, T. F. Kelly, and B. P. Tonner, Rev. Sci. Instrum. 67, 737 (1996)

${ }^{4}$ G. De Stasio, B. Gilbert, L. Perfetti, T. Nelson, M. Capozi, P. A. Baudat, F. Cerrina, P. Perfetti, B. P. Tonner, and G. Margaritondo, Rev. Sci. Instrum. 69, 3106 (1998).

${ }^{5}$ For an extensive and complete review on radiation damage, see N. E. A. Crompton, Acta Oncol. 11, 1 (1998).

${ }^{6}$ T. Parasassi, O. Sapora, A. M. Giusti, G. De Stasio, and G. Ravagnan, Int. J. Radiat. Biol. 59, 59 (1991).

${ }^{7}$ J. H. Hubbell, Radiat. Res. 70, 58-81 (1977).

${ }^{8}$ B. P. Tonner, T. Droubay, J. Denlinger, W. Meyer-Ilse, T. Warwick, J. Rothe, E. Kneedler, K. Pecher, K. Nealson, and T. Grundl, Surf. Interface Anal. 27, 247 (1999).

${ }^{9}$ S. Williams, C. Jacobsen, J. Kirz, J. Maser, S. Wirick, and X. Zhang, Rev. Sci. Instrum. 66, 1271 (1995).

${ }^{10}$ W. Meyer-Ilse, M. Medecki, J. T. Brown, J. M. Heck, E. H. Anderson, A. Stead, T. Ford, R. Balhorn, C. Petersen, C. Magowan, and D. T. Atwood, $X$-Ray Spectroscopy and Spectromicroscopy, edited by J. Thieme, G. Schmahl, D. Rudolph, and E. Umbach (Springer, Berlin, 1998). 